\title{
Utilizing Photogrammetry and Strain Gage Measurement to Characterize Pressurization of an Inflatable Module
}

\author{
Doug Litteken ${ }^{1}$, Molly Selig ${ }^{1}$, and Gerard Valle ${ }^{2}$ \\ NASA Johnson Space Center (JSC), Houston, TX, 77058 \\ Ovidio Oliveras ${ }^{3}$ \\ Jacobs Engineering, Houston, TX, 77058
}

\begin{abstract}
This paper documents the integration of a large hatch penetration into an inflatable module. This paper also documents the comparison of analytical load predictions with measured results utilizing strain measurement. Strain was measured by utilizing photogrammetric measurement and through measurement obtained from strain gages mounted to selected clevises that interface with the structural webbings. Bench testing showed good correlation between strain measurement obtained from an extensometer and photogrammetric measurement especially after the fabric has transitioned through the low load/high strain region of the curve. Test results for the full-scale torus showed mixed results in the lower load and thus lower strain regions. Overall strain, and thus load, measured by strain gages and photogrammetry tracked fairly well with analytical predictions. Methods and areas of improvements are discussed.
\end{abstract}

\section{Introduction}

$\mathrm{I}_{\mathrm{t}}^{\mathrm{n}}$ today's sometimes uncertain environment one thing is certain, soft-good structures have been and will continue to play an important role in the Space Program and there are many opportunities for innovative technology development. Key soft-good structures currently being used in the Space Program include space suits, micrometeoroid / orbital debris protection systems, impact attenuation systems, and numerous material applications (thermal protection, atomic oxygen protection, IVA applications, etc...). Other soft-good opportunities include inflatable modules (such as airlocks and habitats), inflatable aerodynamic decelerators, inflatable sunshields, inflatable solar sails, and inflatable telescopes. Understanding a variety of design, analysis, test, and manufacturing methods and how these various techniques interact is an important part of effectively and efficiently utilizing soft goods for desired space and terrestrial applications.

For this study, NASA embarked on integrating a large hatch/frame penetration into an inflatable module. Integrating a large hatch/frame penetration may become a requirement for large inflatable modules if multiple ports are required to attach multiple modules together.

During TransHab and subsequent testing, the woven restraint construction has been proven to be a damage tolerant, repeatable, and efficient design for a highly loaded fabric structures. The TransHab geometry consisted of a large $23 \mathrm{ft}$ diameter cylinder with end-domes and a metallic central core. For this type of geometry, the maximum membrane stress is based on the $23 \mathrm{ft}$ cylindrical diameter. Therefore, high strength webbing arranged with high areal density is required, resulting in a tightly woven structure. From a structural standpoint a torus has a geometrical advantage over a large cylindrical structure in that the maximum stress is based on the (smaller) crosssectional diameter of the torus rather than the (large) diameter of a similarly sized cylindrical structure. These inherently lower stresses allow alternate, lighter weight, restraint layer constructions to be considered. For the FullScale Torus Test Article (Figure 1), the stress is based on the $12.3 \mathrm{ft}$ diameter toroidal cross-section resulting in a relatively lower membrane stress. Therefore, high strength webbing may be spaced further apart, similar to a cargo net type construction, to carry the global pressure loading. A structural bladder (urethane coated Vectran) is used to support the load between structural webbings. For a flight design a separate carrier fabric and non-loaded lowpermeability bladder layer(s) will probably be required to meet leak rate requirements at pressurization.

${ }^{1}$ Expandable Structures Designer/Analyst, JSC Structural Engineering Division, 2101 NASA Parkway/ES211

${ }^{2}$ Expandable Structures Project Manager, JSC Structural Engineering Division, 2101 NASA Parkway/ES211

${ }^{3}$ Photogrammetry Lead, JSC Structural Engineering Division, 2101 NASA Parkway/ES411 
The Full-Scale Inflatable Module shown in Figure 1, hereafter referred to as the Phase II article, was originally designed to support a deployment and mating test in support of a Lunar Surface Systems (LSS) outpost. Phase I and Phase II articles were to be deployed and mated in a terrestrial environment. New direction outlined in the 2011 President's proposed budget included a focus away from near-term (2020) return to the lunar surface and an increased interest in technology development. Therefore, the focus of this project shifted towards a design limit pressurization test.

Today many man-rated soft good structures (such as airships) use a high, typically 4.0, Factor of Safety on design load to account for a number of unknowns, including: uncertainty in manufacturing techniques, difficulty in predicting load path and frictional effects, and limited ability to accurately measure load during

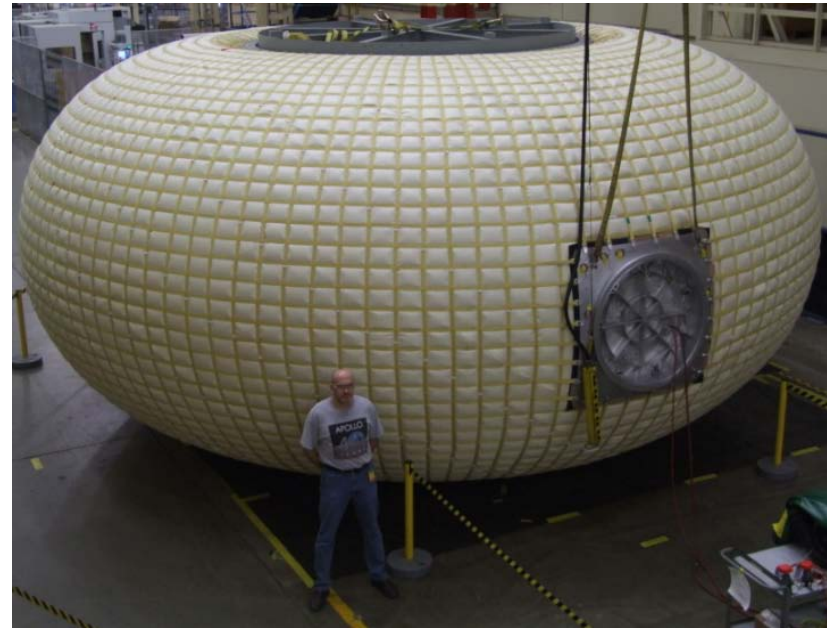

Figure 1. Full-Scale Torus Inflatable Module with “Cargo-Net” Construction. testing and accurately correlate it with analytical predictions. When measuring loads in fabric members many measurement devices can be inaccurate or adversely affect the geometry of the soft-good member that is being investigated. In the past, NASA has applied strain gages to metallic clevises that interface with structural webbings to measure strain and thus calibrated load during pressurization with mixed results. For this study, NASA utilized photogrammetry in addition to strain measurement of calibrated clevises to measure axial strain in the straps during pressurization. Photogrammetry has been utilized successfully on testing of Composite Overwrap Pressure Vessels (COPV) at WSTF and NASA hopes to demonstrate similar results on a soft-goods structure which are much more flexible when compared to COPV. ${ }^{1}$ NASA will utilize photogrammetry by using the ARAMIS software system.

\section{Phase II Test Article Design}

The Phase II test article consists of a load bearing restraint layer, a bladder or gas barrier, and a structural metallic core as shown in Figure 2. The test article restraint layer consists of one in wide Kevlar webbing that is fabricated in cargo net pattern as seen in Figure 1 and 2. The test article is $28 \mathrm{ft}$ in diameter and $12.3 \mathrm{ft}$ in height and weighs approximately 11,000 lbs when assembled with the bulk of the weight coming from the non-flight steel core. The bladder and restraint layer are assembled to a central metallic core structure, which is $12 \mathrm{ft}$ in diameter and $12 \mathrm{ft}$ high, to form a full scale inflatable torus. Underneath the structural restraint layer is the bladder or gas barrier. For this test the bladder was required to maintain pressure for testing only and was not representative of a flight design. The bladder and structural restraint layer attach to the structural core of the module at steel bulkheads at each end. The longitudinal members of the structural restraint layer are attached to the bulkheads using a series of clevises that are bolted to the bulkheads. A 40-in diameter hatch with 49-in structural frame is integrated into the belly of the fabric. Clevises are also mounted to the structural hatch/frame in the longitudinal and hoop directions and interface with the structural restraint layer. Strain gages are placed on the clevises that can measure change in load when the structural restraint is inflated.

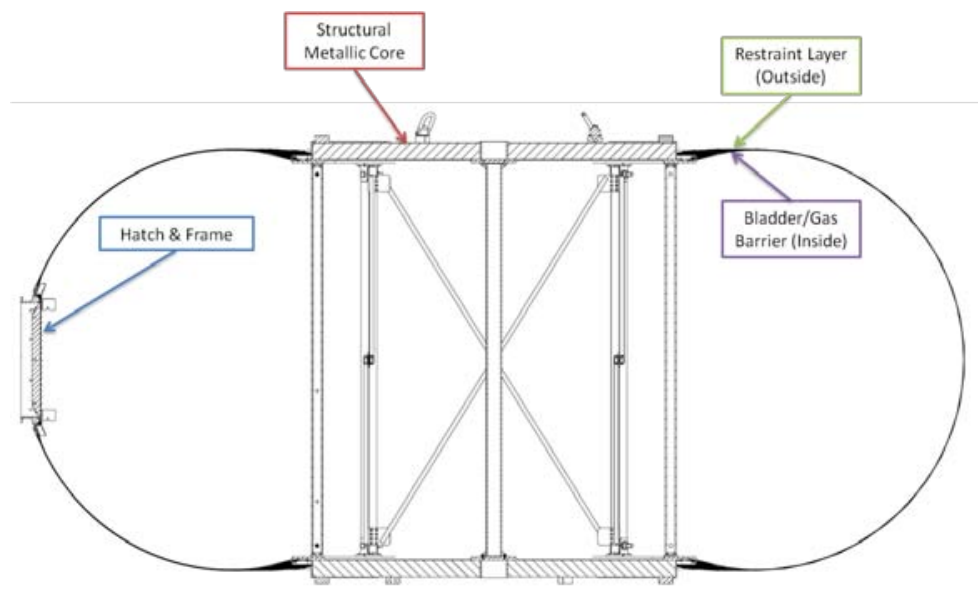

Figure 2. Cross section view of the Phase II test article showing the hatch \& frame, structural metallic core, restraint layer, and bladder/gas barrier. 


\section{Photogrammetry}

The Digital Image Correlation system used in this test program was developed by GOM mbH of Braunschweig, Germany and utilizes a software package called ARAMIS. The ARAMIS software uses the principles of photogrammetry that allows full-field displacement and strain measurements. The system requires spraying high contrast dot patterns onto a sample, which is then tracked in ARAMIS by thousands of correlation areas known as facets. The center of each facet is the measurement point that can be thought of as a 3D digital extensometer. An array of these extensometers forms an in-plane strain rosette. The facet centers are tracked in each successive pair of images, with accuracy up to one hundredth of a pixel.

Figure 3 shows two 5 megapixel video cameras that were used in the test with a $6 \mathrm{ft}$ camera bar, non-standard with the ARAMIS system, fabricated for the purpose of this test. Figure 4 shows an approximate 0.26 in dot pattern used

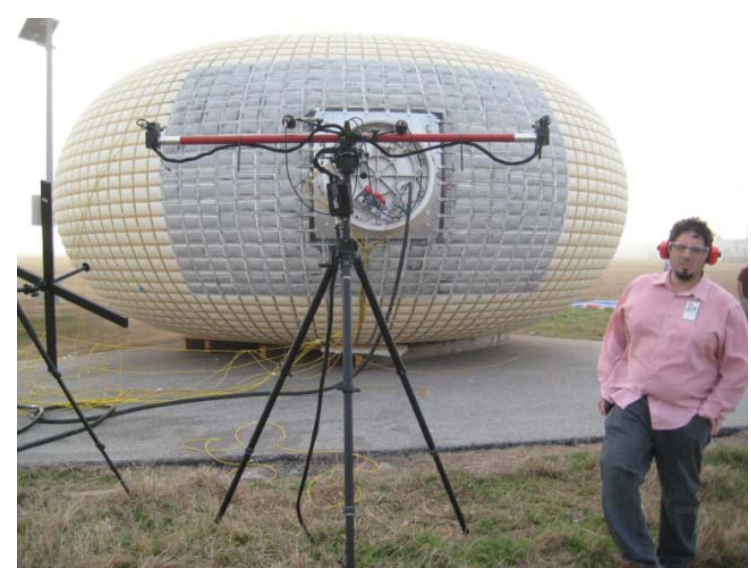

Figure 3. Phase II article with Painted "Dot" Pattern and Photogrammetry Camera System.

on the Phase II article. The dot size was chosen to meet a general criterion that each dot occupies 3 to 5 pixels on the camera sensor.

The digital cameras were used at a resolution of 2448 x 2050 pixels and recorded every 5 seconds, but capable of recording up to 15 frames per second. The ARAMIS cameras work as a stereo pair to create a 3D volume of the area in which the ARAMIS software can take measurements. This volume varies with the angle of the cameras and lens choice. Our camera setup consisted of $12 \mathrm{~mm}$ lenses with the cameras angled at $24.7^{\circ}$, giving a measuring volume of $2,626.3 \mathrm{~mm} /$ 2,306.8 $\mathrm{mm} / 2,306.8 \mathrm{~mm}$. To calibrate for this volume, a $1,200 \mathrm{~mm}$ calibration object type cross was moved in specified locations to calibrate the sensor. Because the effective area that the cross covers was a fraction of the total area needed for an effective calibration, extra steps were taken to cover all four corners for each camera

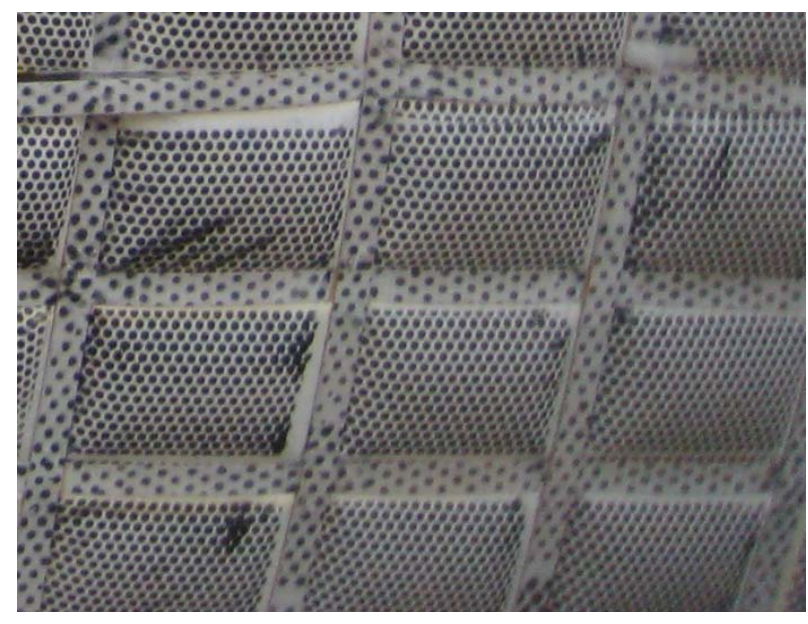

Figure 4. Phase II article with Painted "Dot" Pattern to Support Photogrammetric Analysis (Close-Up). lens. This is done in order to compute any lens distortion that may affect computation of the outer perimeters. The ARAMIS system was able to solve approximately $52 \mathrm{ft}^{2}$ of area on the expandable structure.

The system uses a control unit for synchronizing the cameras. This control unit is capable of accepting several analog and digital inputs. During testing, input from a pressure gage attached to the hatch was recorded and included in the data output.

\section{A. Photogrammetry Calibration Testing}

Calibration testing was performed on 1 in wide Kevlar $12,500 \mathrm{lb} / \mathrm{in}$ webbing to compare photogrammetric strain measurement to the deflection of an extensometer in a tensile testing machine and to produce a load vs. strain curve for photogrammetry analysis. Three webbing samples were tested using Capstan Grips as shown in Figure 5 and Figure 6. Each

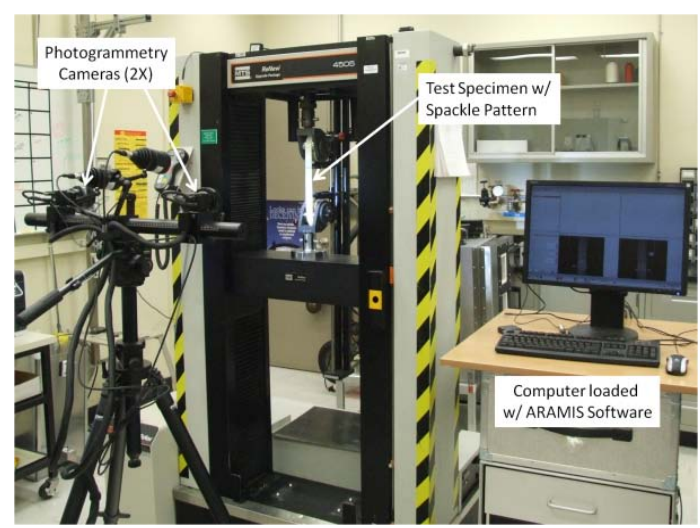

Figure 5. Photogrammetry benchmark testing setup with photogrammetry cameras, ARAMIS software, and test specimen. sample was prepared for photogrammetry by first painting with white paint, then applying a black speckle pattern to support strain measurement. Extensometers were placed on the 
test samples with a gage length of 4 in. During testing, each strap was loaded to approximately 8,000 lbf. Photogrammetric strain measurements were taken at the left, center, and right portions along the width of the strap to see how measurements varied.

Photogrammetric testing data showed a slight variation in the strain measurement between the left, center, and right locations along the width of the strap. Although this variation was not significant, it is worth noting that the center location measured the maximum strain between the three locations, and was thus chosen as the primary measurement location for photogrammetry strain measurement on future tests.

Compared to the extensometer, the photogrammetry strain measurement showed smaller values of strain for a given load, but followed the same stress-strain relationship. Stretch in the strap material as it is loaded may cause this variation along with differences in test setup and alignment between runs.

From this testing, load vs. strain curves were created for future photogrammetry use. Just as strain gages are calibrated, photogrammetry benchmark testing allowed a known load to pull the strap, while the photogrammetry system measured the strain. The relationship between this measurement and the applied load are plotted as shown in Figure 7.

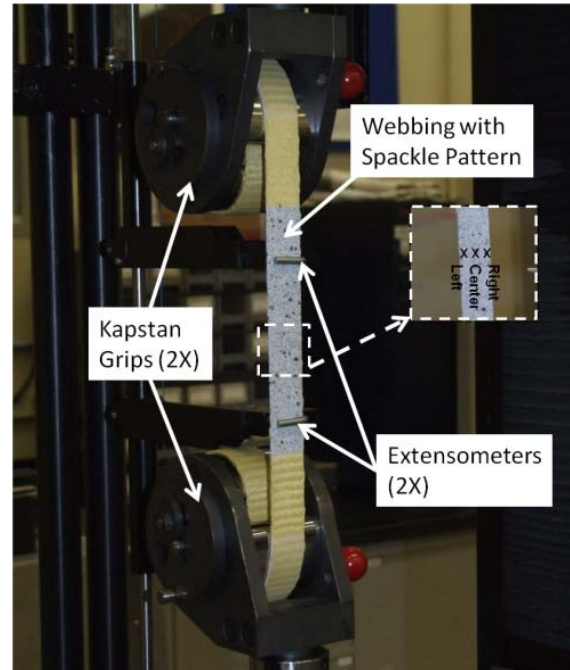

Figure 6. Kevlar webbing in tensile testing machine for photogrammetryl benchmark testing.

There are two important regions on this curve, where the load vs. strain relationship differs. Below 2,000 lbf, the relationship is quadratic and can be expressed by a quadratic equation as shown in the figure. Above 2,000 lbf, the load vs. strain relationship is linear and can be expressed by a linear equation, also shown in the figure. This dual region curve is characteristic of webbing straps tested as they initially stretch before fully taking load. During fullscale pressurization tests of the Phase II Article, this calibration curve is used to analyze test data by converting measured photogrammetric strain to load.

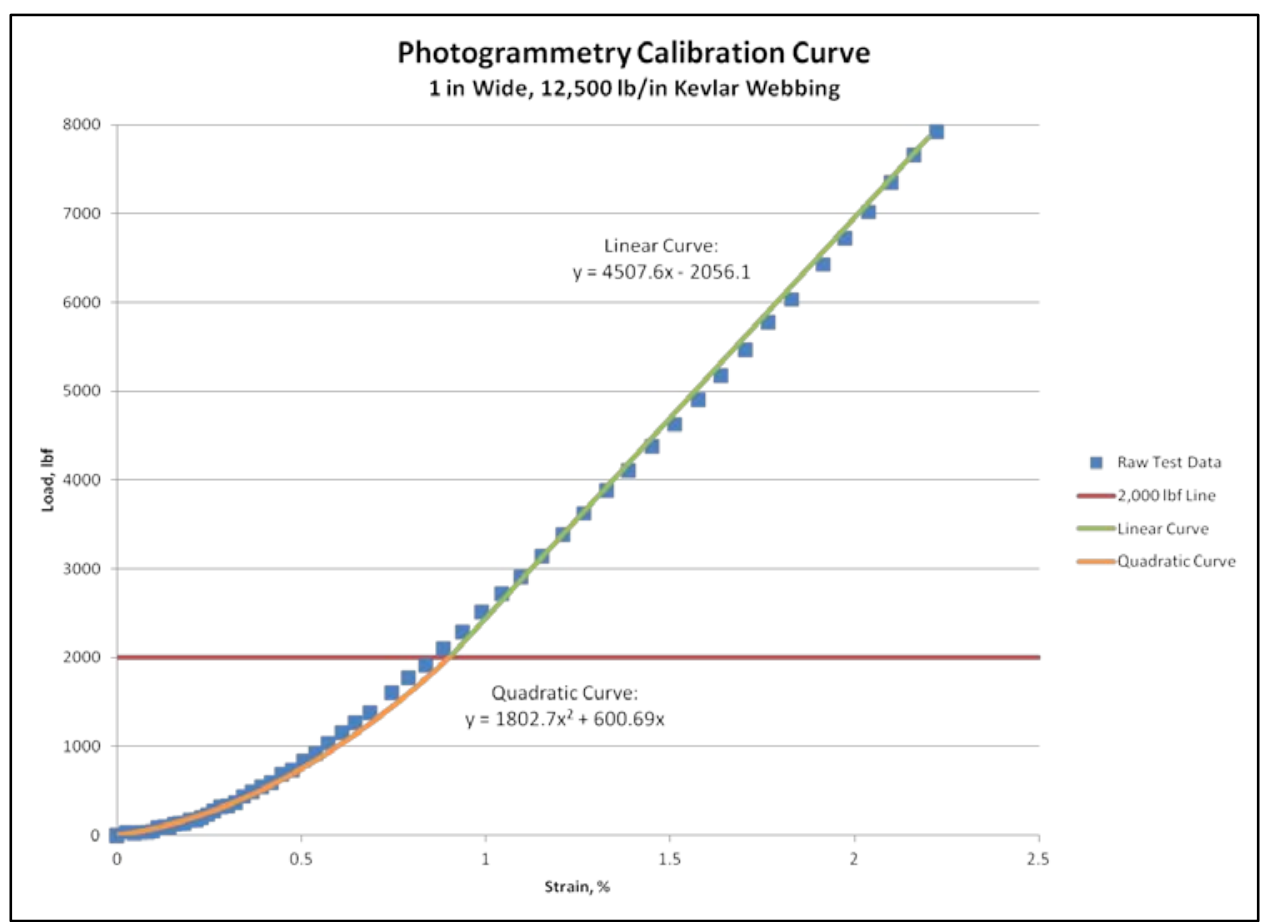

Figure 7. Load vs. Pressure Photogrammetry Calibration Curve generated from benchmark photogrammetry testing. Includes testing data and best fit lines for both quadratic and linear region. Also shows 2,000 lbf transition line. 


\section{Phase II Test Objectives}

The objectives of the Phase II tests are to validate assumptions related to the integration of a hatch structure into an inflatable module, and to correlate analytical predictions of strap loading with measured strain/load utilizing strain gages and photogrammetric strain measurements.

\section{Phase II Pre-test Assumptions}

1. At low pressure, scatter in strain gage measurements is expected. However, first order trends will be present. Low pressure strain gage measurements should provide insight into future placement and the capabilities of the strain gages.

2. Strain measurement as measured by the photogrammetry cameras is expected to provide good data locally and globally.

\section{Pre-Test Analytical Predictions}

Analysis of the test article was performed using a process developed and refined during the TransHab project. The calculation uses standard membrane stress equations for thin walled pressure vessels to generate strap loads. The analysis also accounts for factors such as strap spacing or overlap, seam efficiency, and the non-uniform loading of hoop straps in the toroidal section for the purposes of designing the test article.

The geometry of the Phase II test article is different from most of the articles in the TransHab project. The Phase II test article geometry is purely toroidal, there is no cylindrical section. A toroidal geometry, as shown in Figure 8, can have fewer straps and lower strap loads than similar modules with cylindrical sections.

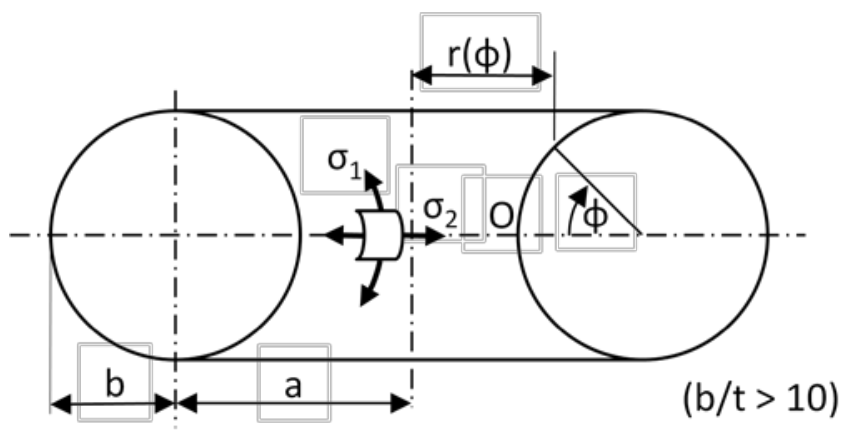

Figure 8. Toroid shape diagram.

The equation for axial stress in a toroidal pressure vessel, where $q$ is the internal pressure and $t$ is the shell wall thickness, is

$$
\sigma_{1}(\varphi)=\frac{q b}{2 t} \frac{r(\varphi)+a}{r(\varphi)}
$$

The equation for hoop stress in a toroidal pressure vessel is

$$
\sigma_{2}=\frac{q b}{2 t}
$$

The test article is made up of 240 longitudinal straps and 40 hoop straps. Hoop straps are equally spaced, and longitudinal straps are grouped in pairs, with each longitudinal pair equally spaced around the test article.

The load per thickness of each longitudinal strap, $P_{1}$, where $n_{1}$ is the number of longitudinal straps and $w$ is the width of the straps, is

$$
P_{1}(\varphi)=\sigma_{1}(\varphi) \frac{2 \pi r(\varphi)}{n_{1} w}
$$

The load per thickness of each hoop strap, $P_{2}$, where $L_{1}$ is the length of the longitudinal strap and $n_{2}$ is the number of hoop straps, is

$$
P_{2}=\sigma_{2} \frac{L_{1}}{n_{2} w}
$$

Hoop straps are numbered from the top of the test article to the bottom. The test pressure was defined as 5 psig (55\% of the 9 psig design pressure). The predicted strap loads are shown in Figure 9 below. Since the longitudinal strap load is a function of angular position, the predicted load varies according to where the photogrammetry measurements were taken. The predicted loads are linear between 0 and 5 psi.

$$
5
$$

American Institute of Aeronautics and Astronautics 


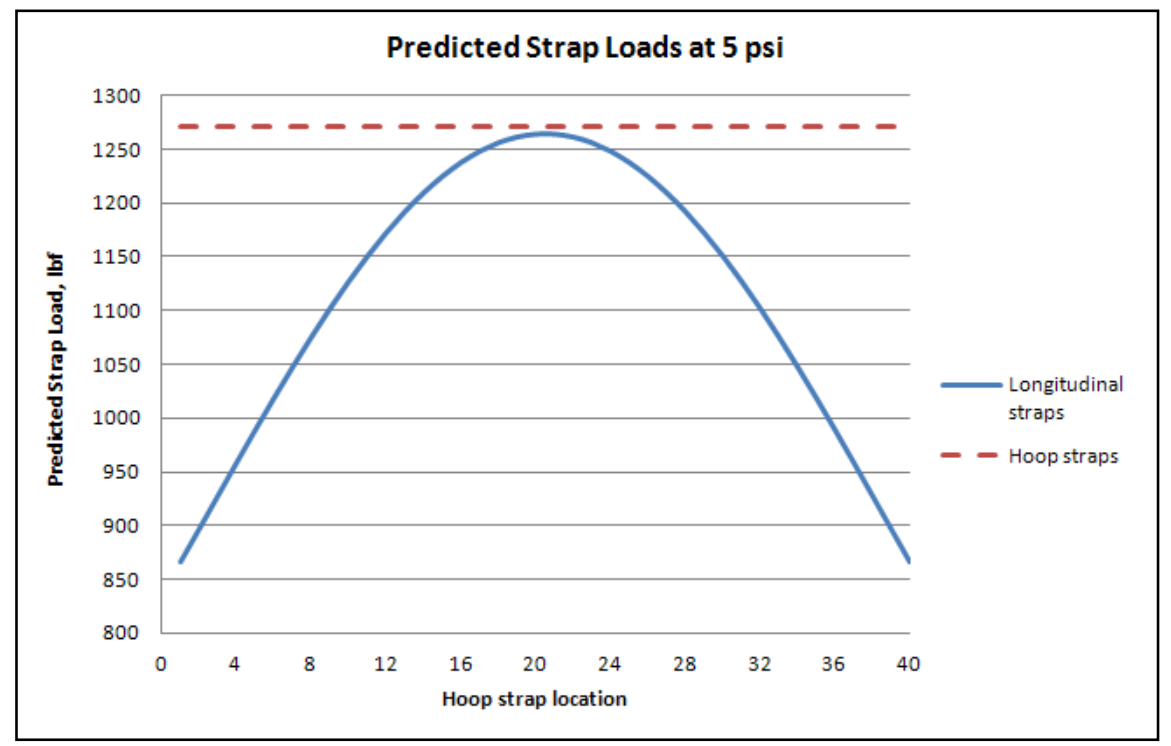

Figure 9. Predicted strap loads for both axial/longitudinal and hoop straps.

\section{Instrumentation}

The Phase II test article includes seven strain gages that are attached to the roller/clevis assemblies which attach the strap restraints to the hatch/frame. The gages are arranged as shown below in Figure 10 with four gages mounted on clevises that interface with cylindrical hoop straps and three gages mounted on clevises interfacing with axial/longitudinal straps. After installation of each strain gage, calibration was performed to establish the relationship between strain and axial load in the strap.

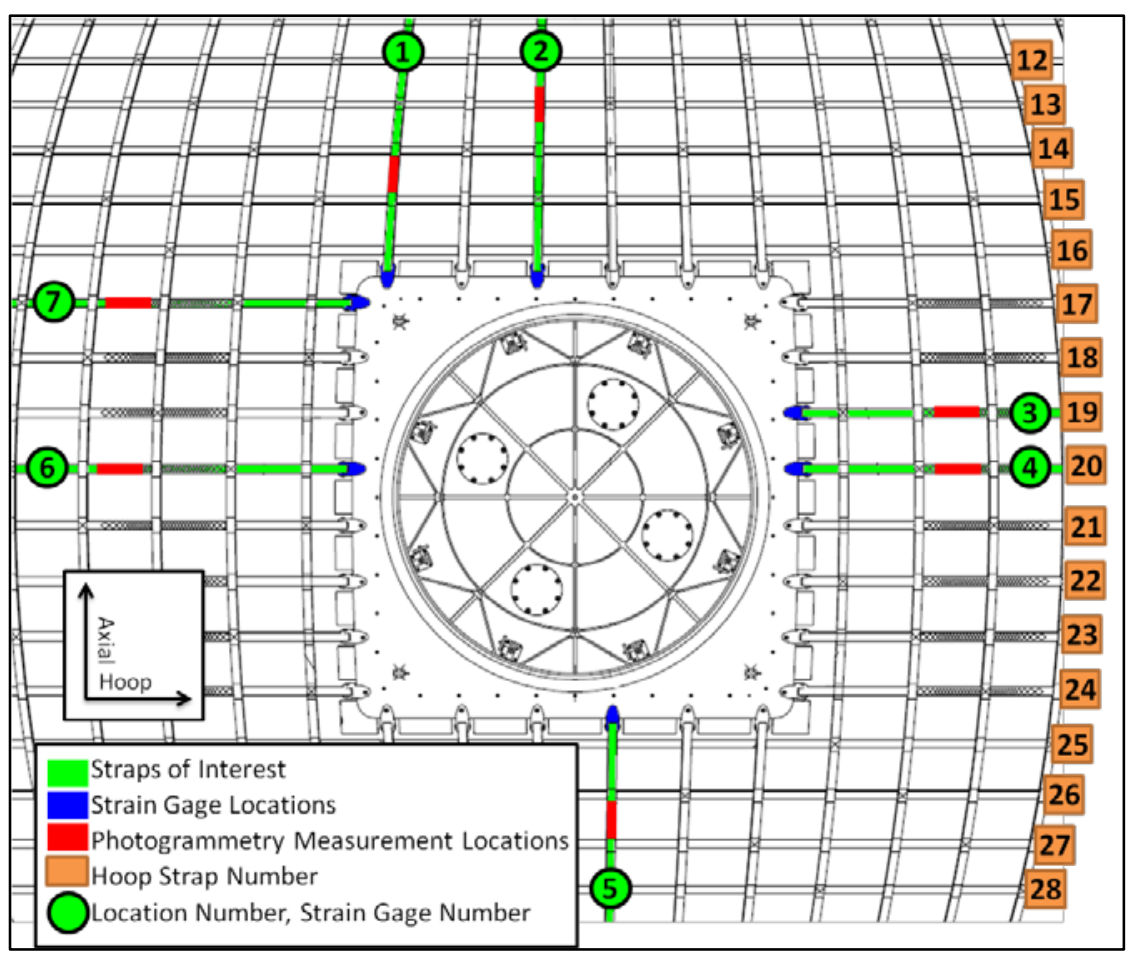

Figure 10. View of Phase II Hatch/Frame showing strain gage and photogrammetry measurement locations. 


\section{Testing of the Phase II Article}

Low pressurization testing of the Phase II article was completed on 02/18/2011 at the Energy Systems Test Area (ESTA) at Johnson Space Center (JSC) in Houston, TX. Inflation of the test article was done in a series of step increments, allowing time between steps to complete system checks and for technicians to approach the test article if needed. Because of the potential danger of the fully inflated article, no personnel may approach the structure until it has been pressure proofed to at least twice the approaching pressure. For example, the article was pressurized to 5 psig and then lowered back down to 2 psig, a level at which technicians could approach it safely. The pressure was held at 2 psig, which allows the article to take shape and gives personnel time to adjust straps if needed and ensure everything is aligned properly before pressurization proceeds. After adjustment was completed, pressurization continued at a rate of $0.05 \mathrm{psi} / \mathrm{min}$ to a maximum pressure of $5.22 \mathrm{psig}$. The pressure was held there for $5 \mathrm{~min}$, and then slowly released to deflate the article.

\section{B. Data Reduction}

Throughout the entire pressurization process, strain gage and photogrammetric measurements were taken and recorded for this low pressurization test of the Phase II article. Additionally, two pressure sensors and a thermocouple were installed on the hatch and used to record pressure and temperature inside the article. The strain gage output data was converted from strap strain to strap load using the defined calibration curves for each gage, as established during gage installation, as mentioned in Section VII. The strain measurements from photogrammetry analysis were converted to load using the calibration curves defined by the photogrammetry benchmark testing as explained in Section II-A.

In order to compare strain gage data and photogrammetry data side by side, the photogrammetry data had to be adjusted. In the axial direction, the load in the strap varies depending on the location of the measurement, as outlined in Section VI and shown in Figure 9. For example, Figure 10 shows that the photogrammetry measurements of strap 1 and 2 are in different locations and thus have different predicted loads. In order to compensate for this difference, the data for these straps was scaled so that its prediction value matched the prediction value of the strain gages. This scaling was done for all the axial photogrammetry locations. In the hoop direction, the photogrammetry measurements were taken in a location of a strap seam. Figure 10 shows the location of strap seams on the left and right side of the hatch. They are shown with cross-stitching over the strap and span the length between three axial straps. This stitch has two straps on top of one another and forms a loop that connects to the clevis and hatch. Because there are two straps, and the photogrammetry was collected at this location, the data it collected is actually twice as high as it should be. Therefore, the test data was divided by two in order to get the proper readings. This reduction was done for all photogrammetry hoop measurements. The results of these data adjustments are shown in the following plots where both the strain gage and photogrammetry data is compared to the strain gage prediction values.

\section{Results}

Load measurement determined from calibrated strain gages produced good but somewhat mixed results. Looking at Figure 11, the measured loads in the hoop direction (gages 3, 4, 6, and 7) tracked fairly well with the analytically predicted values. Load measurement determined from individual strain gages 3, 4, 6, and 7 were an average of $17 \%, 17 \%,-39 \%$, and $3 \%$ relative to predicted values, respectively, from $1-5$ psig (see Table 1 ). Clevis strain gages see bending loads in additional to axial strain and can produce variations in strain and thus load measurements. These types of results are consistent with previous inflatable structure testing where strain gaged clevises interface with structural webbings. ${ }^{2}$ Two of the axial gages (2 and 5) tracked slightly higher than analytical predictions (15\% and 16\%, respectively, from 1 to 5-psig) as shown in Figure 12 and Table 1 . However, at 5 psig, gage 1 measured strain and thus load and average of $54 \%$ higher than the analytical prediction from 1 to 5 psig. All other strain gages produced much better correlation with analytical predictions. The photogrammetric measurements corresponding to the structural strap that interfaces with clevis/strain gage 1 produced result more in line with analytical predictions. It is for those reasons; the authors question the accuracy of the clevis/strain gage 1 readings. The average values measured by the strain gages tracked fairly well with the analytical predictions (see Figure 13 and Table 1$)$.

The strain measurements taken from photogrammetry system produced some scatter in distribution but in most cases the linear curve fit generated from the distributed data, tracked fairly well with analytical predictions. For the hoop straps the photogrammetry measurements taken from the straps that interface with strain gaged clevises $3,4,6$, and 7 , tracked fairly well an average of $34 \%, 11 \%,-8 \%$, and $4 \%$, respectively, when compared with analytical predictions from 1 to 5 psig (See Figure 14 and Table 1). For the axial straps the photogrammetry 
measurements taken from the straps that interface with strain gage clevises 1, 2, and 5 tracked fairly well, $-18 \%$, $18 \%$, and $-14 \%$, respectively, with analytical predictions from 1 to 5-psig (See Figure 15 and Table 1). Average hoop and axial strap photogrammetry tracked fairly well with analytical predictions with the average hoop photogrammetry measurements slightly over the analytical predictions after 1.5 psig and the average axial photogrammetry measurements slightly under analytical predictions (see Figure 16 and Table 1).

Figure 17 shows photogrammetry and strain gage measurements for the individual hoop straps and compares them with analytical predictions. Despite variation in individual measurements, average measurements track fairly well with analytical predictions (Figure 18). Figure 19 shows photogrammetric and strap measurements for the individual hoop straps and corresponding analytical predictions. Once again, despite variations in individual measurements, when measurements are averaged they track fairly well with analytical predictions (see Figure 20). All measurements taken during this test were in the low pressure region where loading in the straps were below 2,500 lb for the axial straps and 1,250 lb for the hoop straps. As described in Section III-A, for photogrammetry measurements, the linear portion of the curve starts around 2,000 lb loading so most of the photogrammetry results are in the quadratic prediction region, and only the axial straps are entering the linear region above 4 psig.

Table 1. Average Percent Difference Between Analytical Predictions and Strain Gage and Photogrammetric Measurement between 1-5 psig and at 5 psig.

\begin{tabular}{|l|c|c|c|}
\hline & $\begin{array}{c}\text { Avg. \% diff. } \\
\text { 1-5 psig }\end{array}$ & $\begin{array}{c}\text { \% diff } \\
\text { @ 5 psig }\end{array}$ & \\
\hline \hline s.g. 1 measured (axial) & $54 \%$ & $54 \%$ & \\
\hline photo. 1 measured (axial) & $-18 \%$ & $-10 \%$ & \\
\hline s.g. 2 measured (axial) & $15 \%$ & $14 \%$ & \\
\hline photo. 2 measured (axial) & $18 \%$ & $12 \%$ & \\
\hline s.g. 5 measured (axial) & $-16 \%$ & $-1 \%$ & \\
\hline photo. 5 measured (axial) & $-14 \%$ & $-11 \%$ & \\
\hline \hline s.g. 3 measured (hoop) & $17 \%$ & $20 \%$ & \\
\hline photo. 3 measured (hoop) & $34 \%$ & $41 \%$ & \\
\hline s.g. 4 measured (hoop) & $17 \%$ & $28 \%$ & \\
\hline photo. 4 measured (hoop) & $11 \%$ & $20 \%$ & \\
\hline s.g. 6 measured (hoop) & $-39 \%$ & $-14 \%$ & \\
\hline photo.6 measured (hoop) & $-8 \%$ & $3 \%$ & \\
\hline s.g. 7 measured (hoop) & $3 \%$ & $6 \%$ & \\
\hline photo. 7 measured (hoop) & $4 \%$ & $14 \%$ & \\
\hline \hline Avg s.g. (axial) & $-0.8 \%$ & $6.5 \%$ & 5.g 1 data ommitted from avg. \\
\hline Avg s.g. (hoop) & $9.0 \%$ & $25.8 \%$ & \\
\hline Avg. photo. (axial) & $7.0 \%$ & $35.7 \%$ & \\
\hline Avg. photo. (hoop) & $5.7 \%$ & $24.3 \%$ & \\
\hline
\end{tabular}




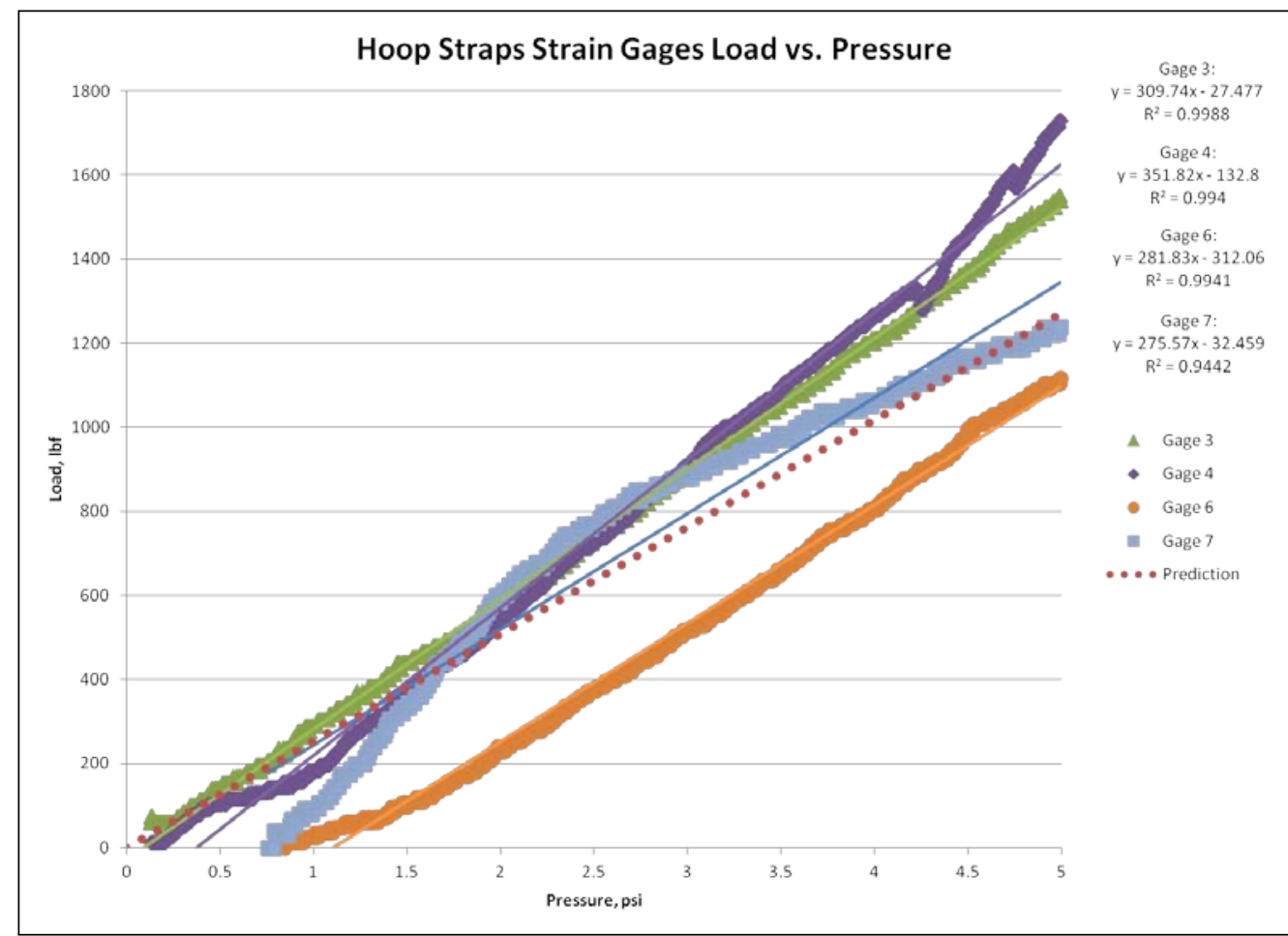

Figure 11. Load vs. pressure from strain gage measurements of straps in the hoop direction. Includes measured strain gage data with linear fit and analytical predictions.

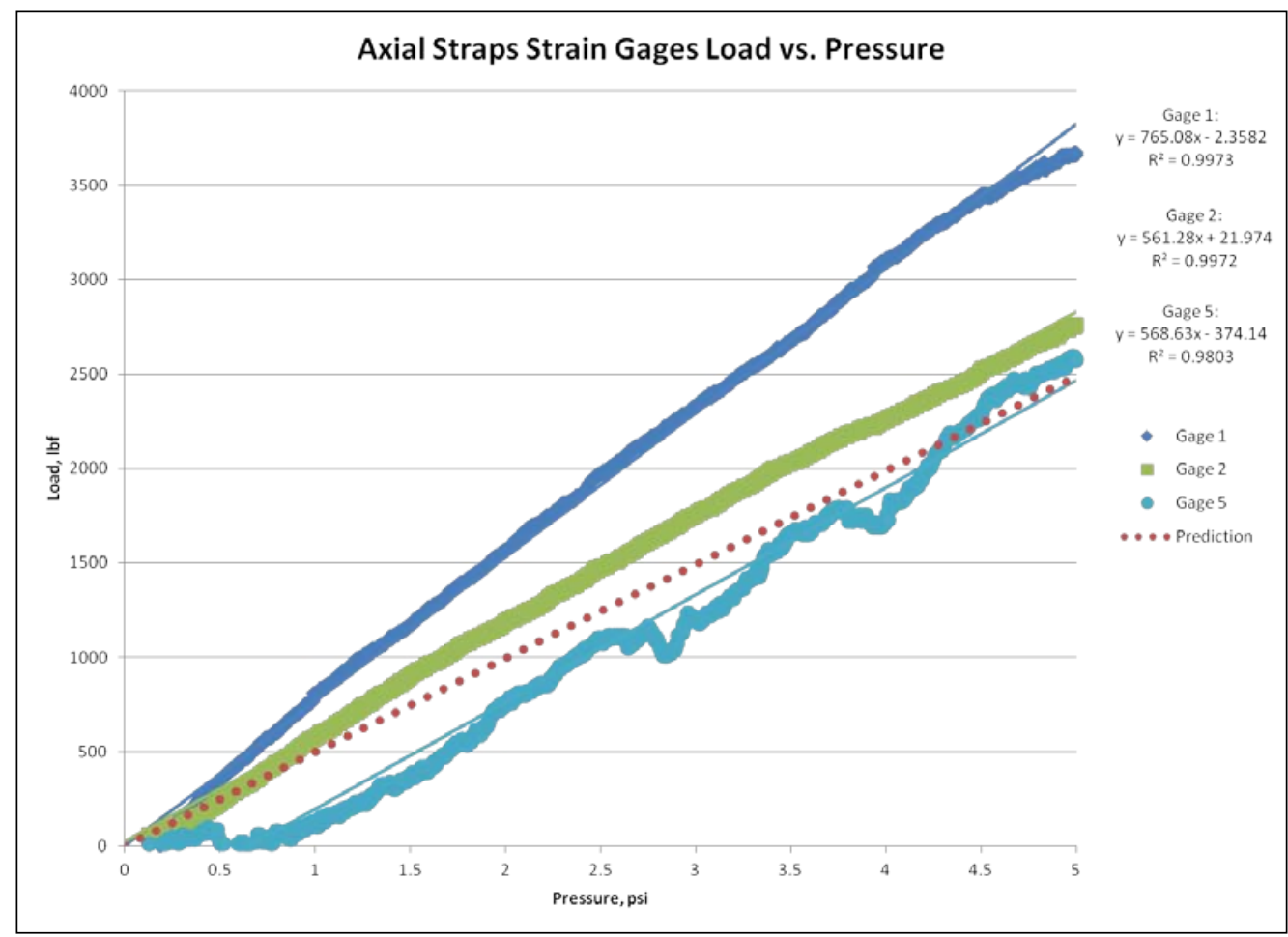

Figure 12. Load vs. pressure from strain gage measurements of straps in the axial direction. Includes measured strain gage data with linear fit and analytical predictions.

American Institute of Aeronautics and Astronautics 


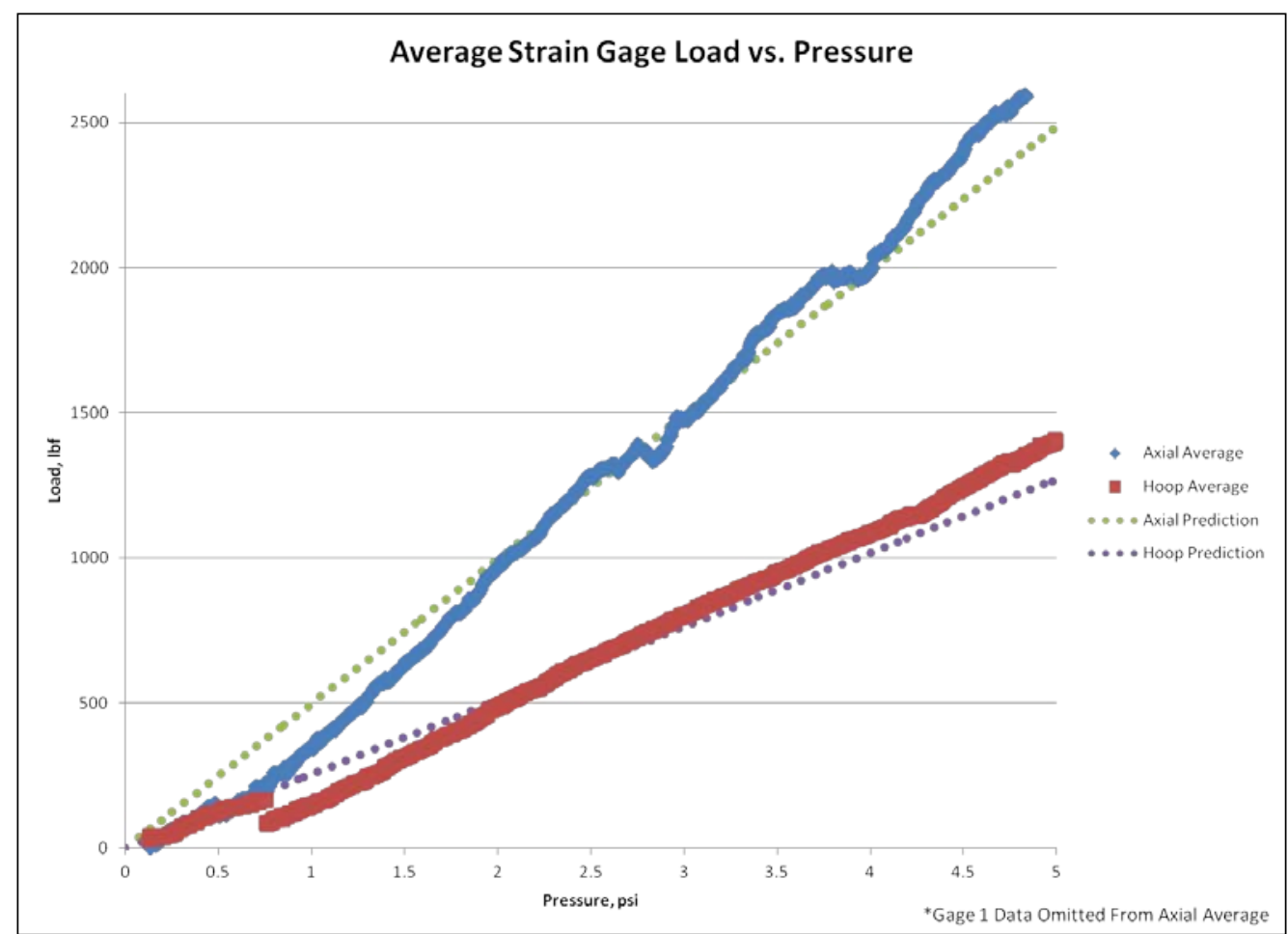

Figure 13. Load vs. pressure of strain gage measurements in both the hoop and axial directions. Includes an average of measured strain gage data in each direction with linear fit and analytical predictions.

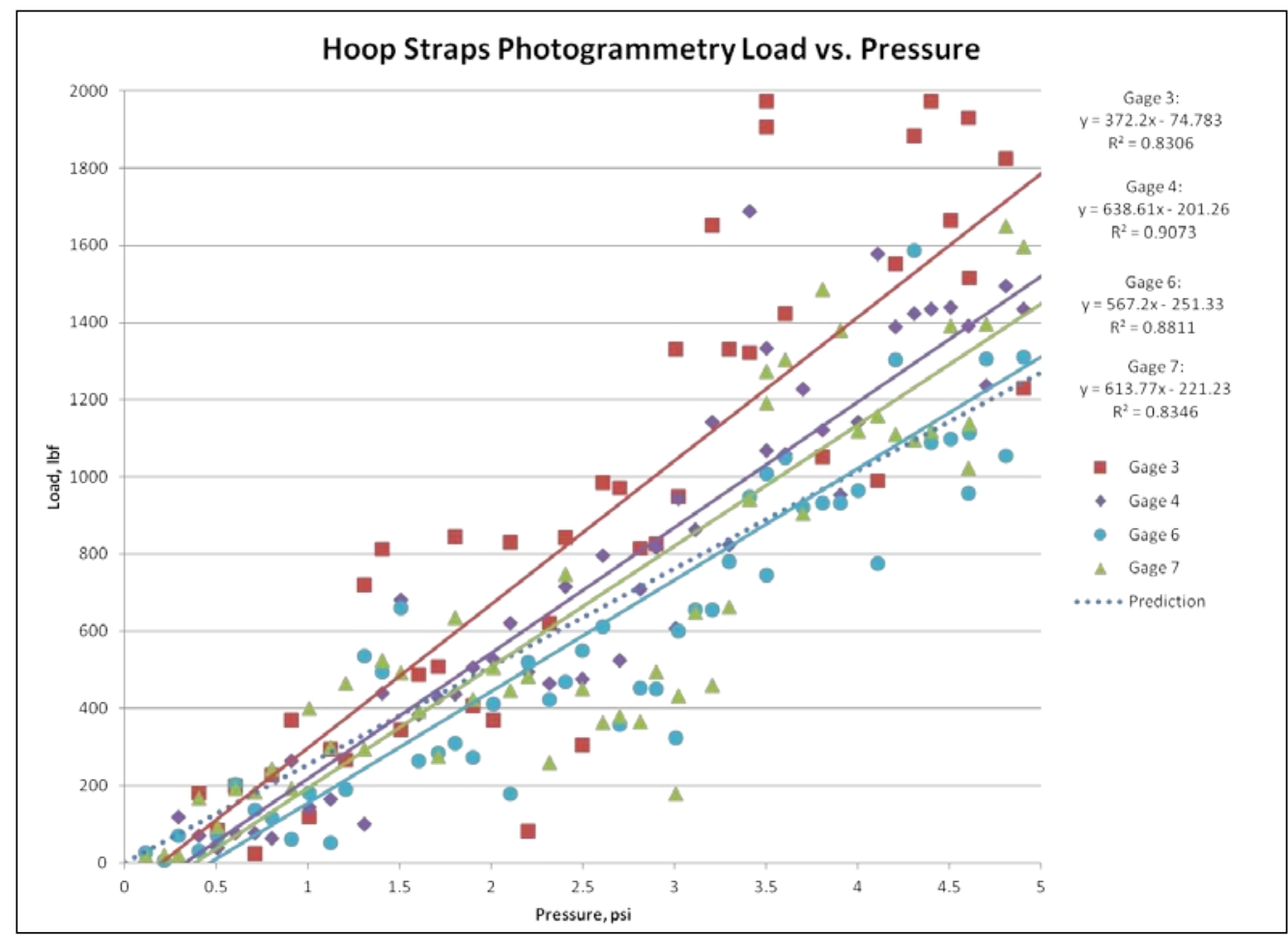

Figure 14. Load vs. pressure from photogrammetry measurements of straps in the hoop direction. Includes measured photogrammetry data with linear fit and analytical predictions. 


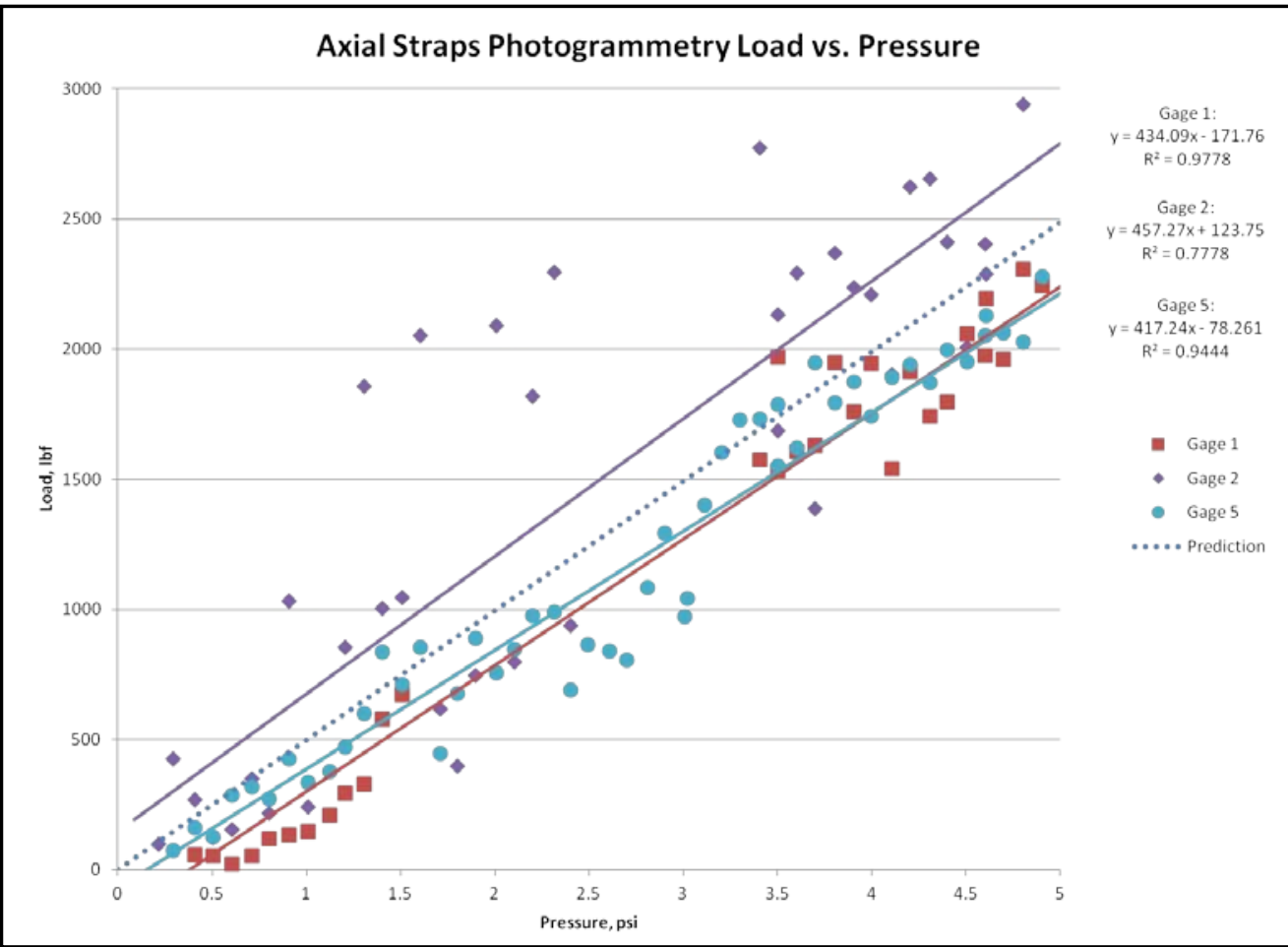

Figure 15. Load vs. pressure from photogrammetry measurements of straps in the axial direction. Includes measured photogrammetry data with linear fit and analytical predictions.

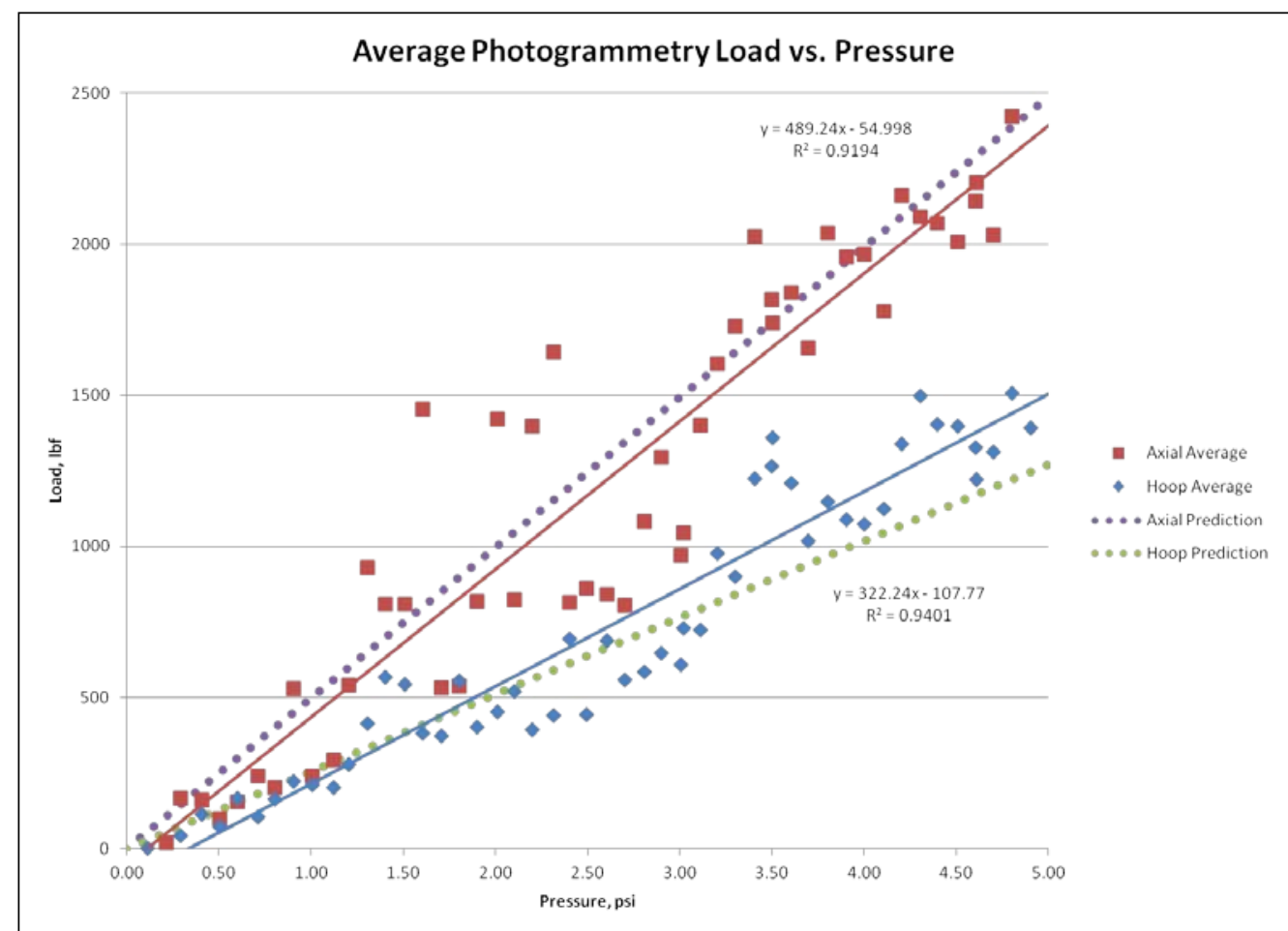

Figure 16. Load vs. pressure of photogrammetry measurements in both the hoop and axial directions. Includes an average of measured photogrammetry data in each direction with linear fit and analytical predictions.

11

American Institute of Aeronautics and Astronautics 


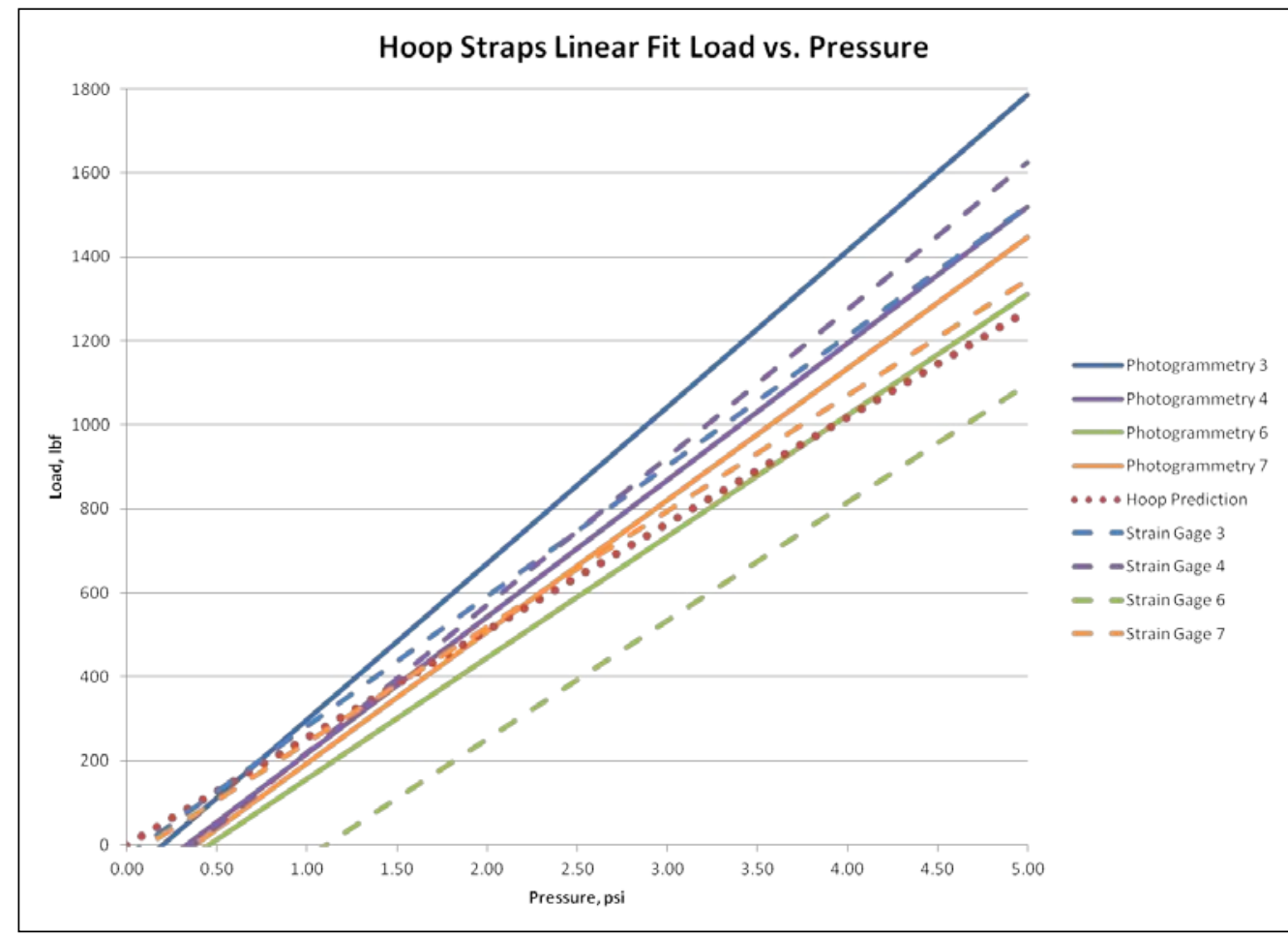

Figure 17. Load vs. pressure of strain gage and photogrammetry measurements in the hoop direction. Includes a linear fit curve representing the measured strain gage and photogrammetry data at each hoop strap location and analytical predictions.

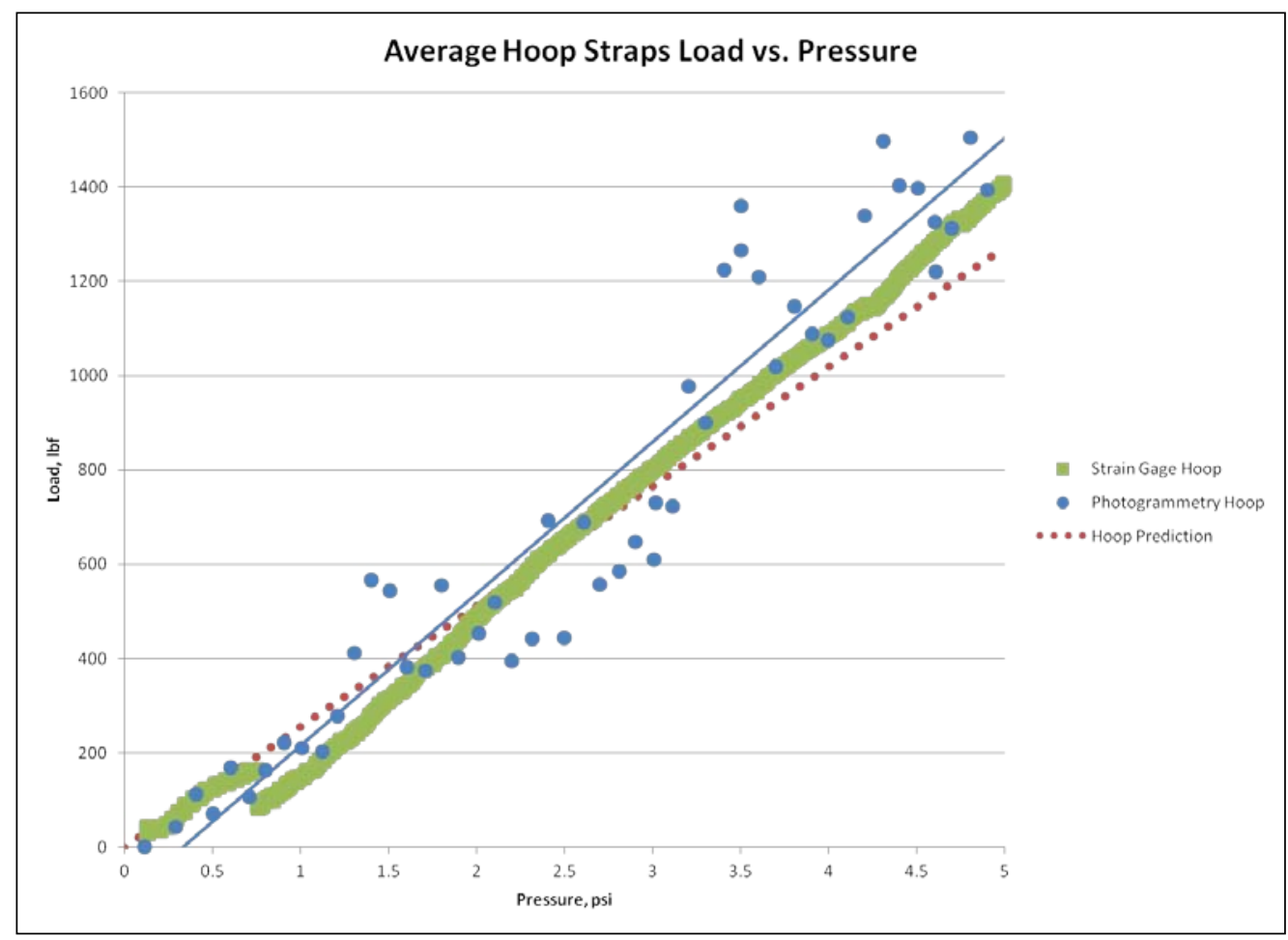

Figure 18. Load vs. pressure of strain gage and photogrammetry measurements in the hoop direction. Includes an average of measured strain gage and photogrammetry data in the hoop direction with linear fit and analytical predictions.

American Institute of Aeronautics and Astronautics 


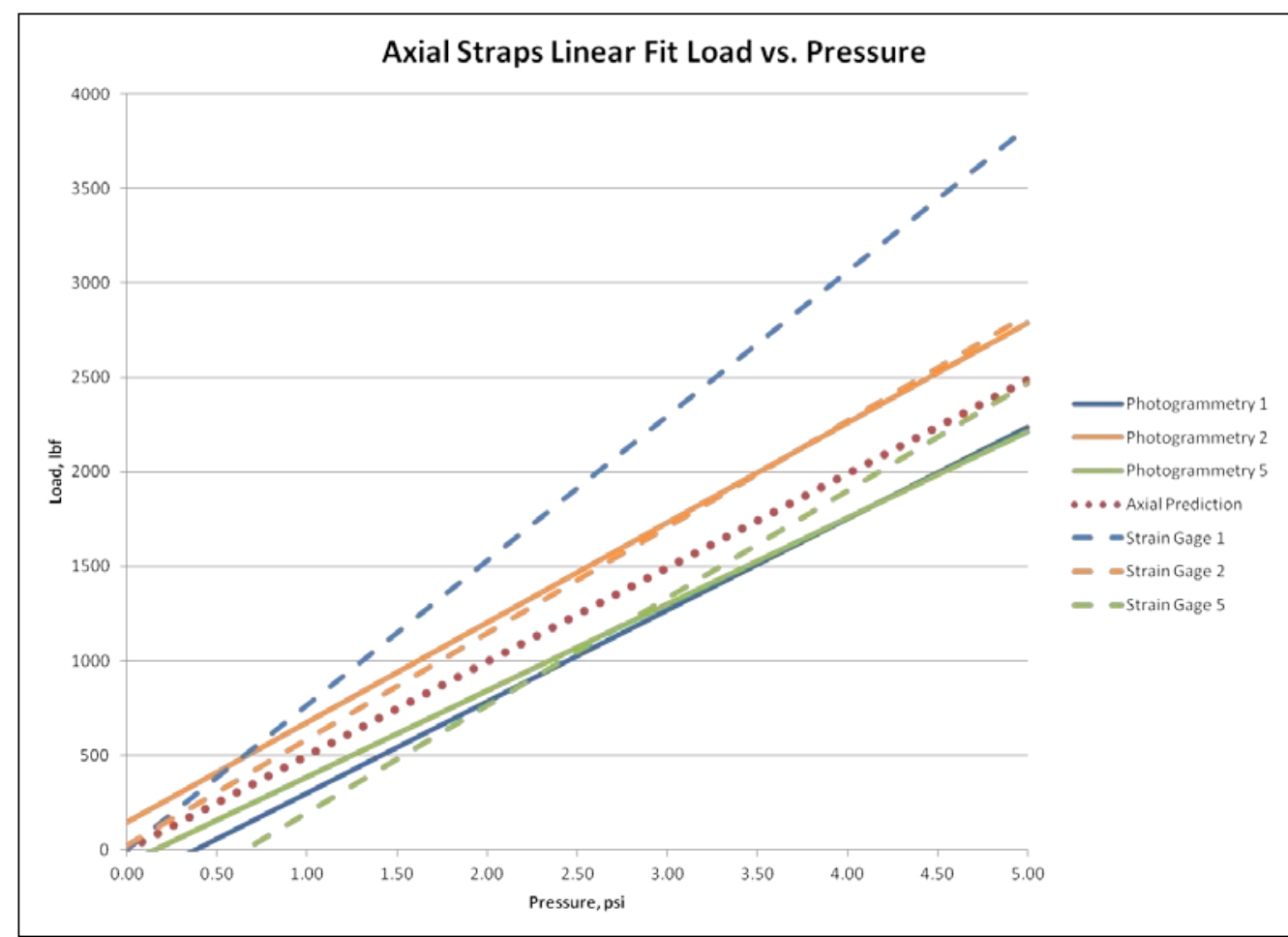

Figure 19. Load vs. pressure of strain gage and photogrammetry measurements in the axial direction. Includes a linear fit curve representing the measured strain gage and photogrammetry data at each axial strap location and analytical predictions.

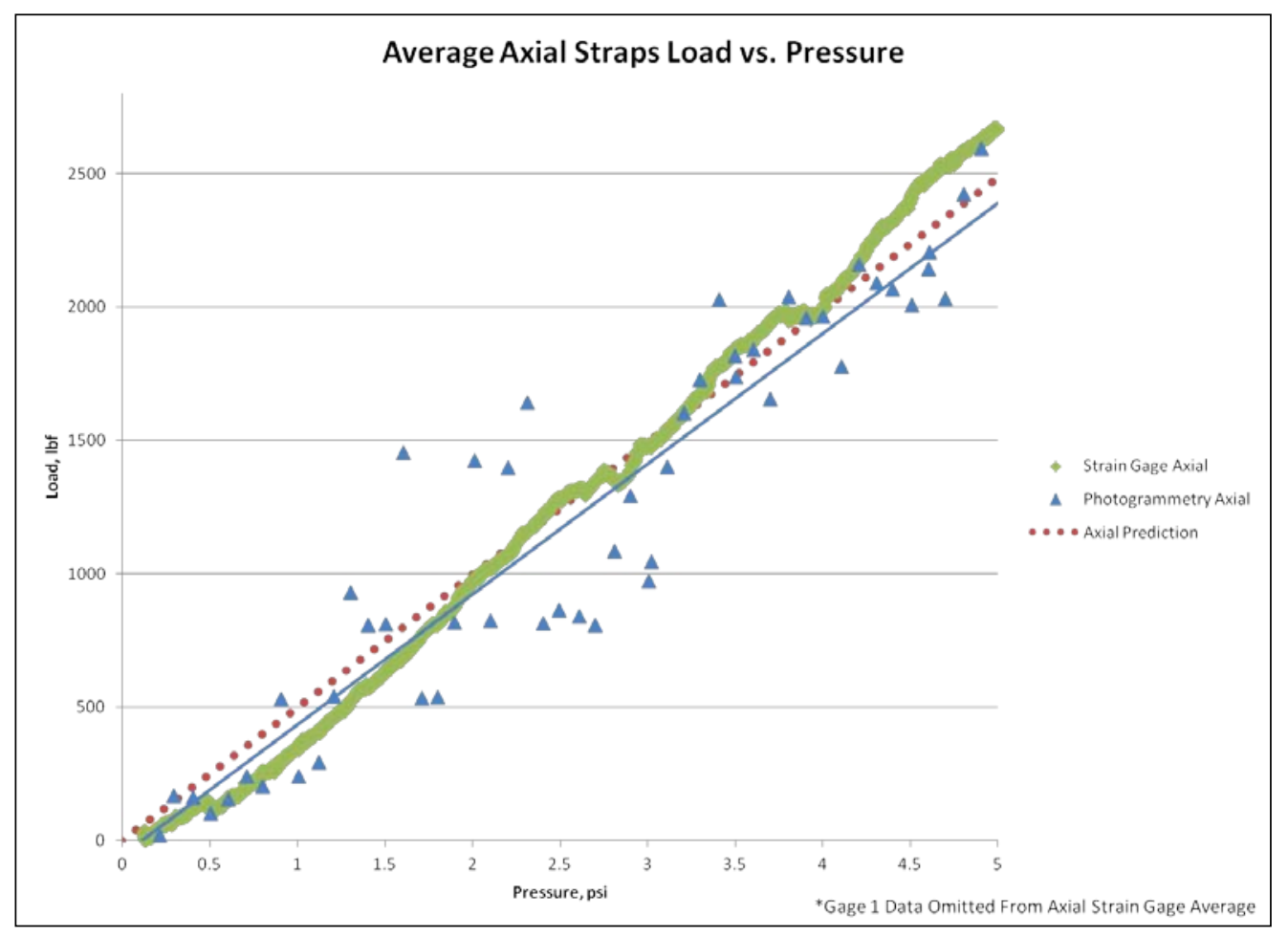

Figure 20. Load vs. pressure of strain gage and photogrammetry measurements in the axial direction. Includes an average of measured strain gage and photogrammetry data in the axial direction with linear fit and analytical predictions.

American Institute of Aeronautics and Astronautics 


\section{Conclusions/Future Work}

\section{A. Photogrammetry Conclusions}

Data acquisition of large structures is a difficult undertaking by itself. Data acquisition of an expandable structure with different interfaces is even more of a challenge. Field of view is the first step when working with any structures, it is what determines the distance, lens, camera separation, camera angle and dot size that should be used for any given test.

For the Phase II expandable structure, the plan was to capture as much surface area of the article as possible in a single pressurization and from that data, analyze just a few small sections. With a large field of view, the camera is observing gross movement and strain, but when measuring a relatively small strap that is far away, there will be environmental noise introduced in the data. When done outside, there are many possible sources that affect the data. Lighting is a big issue, like facing the camera to a transient sun, or having some cloud coverage. Changes in temperature can also slightly change camera orientation relative to each other, which makes them go out of calibration ever so slightly.

Another difficult task with large structures is dot size. A 5 pixel diameter dot size is a good minimum when working with a large structure. Relatively speaking, the Phase II test required a much higher dot count with a large field of view than the small speckle pattern and small file do view used on the benchmark test. However, the ARAMIS does not track dots, but rather groups of dots. The software uses square facets to track deformation and movement. Each facet is composed of a group of dots that both cameras can detect and resolve its location in a three dimensional volume. If the facet falls between the interface of two different materials, like the interface between the restraint layer and the bladder material in the Phase II article, a higher facet deformation is seen, which incorrectly influences the data. With a large size, a facet at an interface could deform, making the center of the facet on a point to point measurement change overall length by 0.01 in. At a length of three or four inches, a change of $+/-0.005$ in to $+/-0.01$ in from the true value can also create very noisy data, especially when that three or four inches is a relatively very small section of a larger picture.

Figure 21 and Figure 22 below show the difference between a large and a small field of view. On both

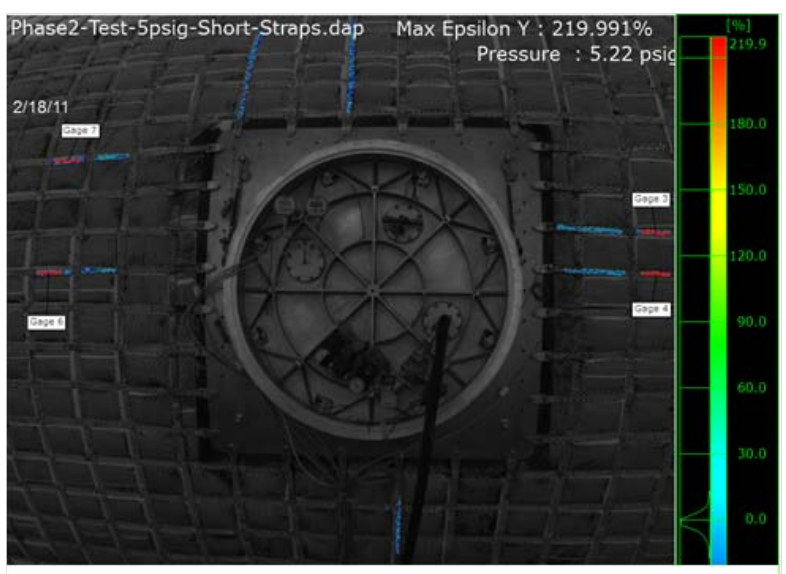

Point to Point Strain Measurement

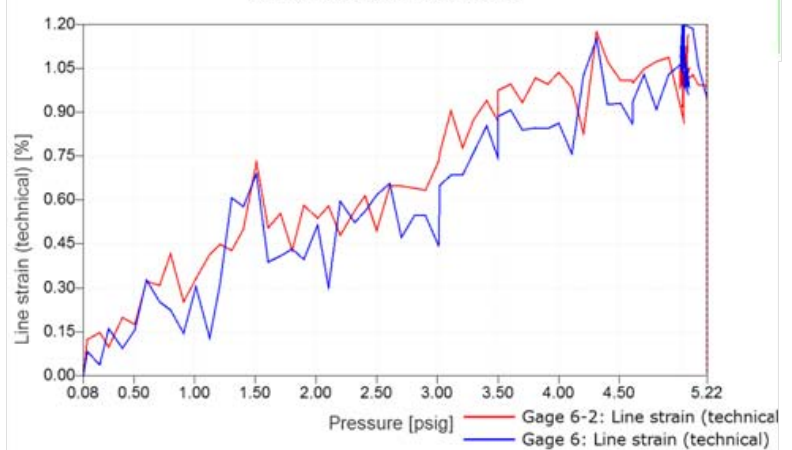

Figure 21. Large field of view on Phase II test article and resultant strain vs. pressure curve.

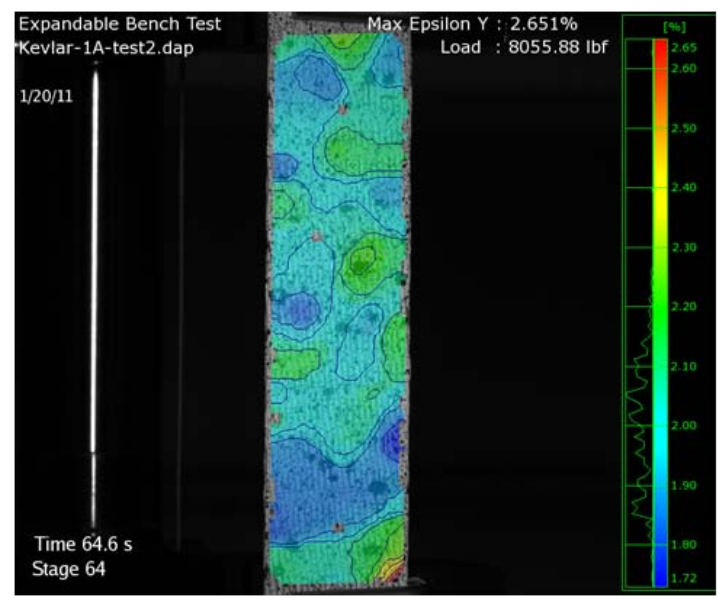

Expandable Bench Test
Point to Point Strain Measurement

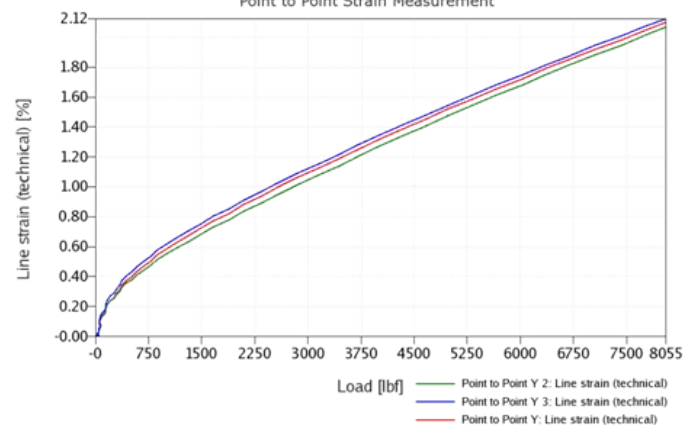

Figure 22. Small field of view from benchmark testing and resultant strain vs. load curve. 
instances, the length of the line strain was about three to four inches, but because we can cover more pixels the closer we are, we are not affected by subtle deformation that changes the location of the center of the facet as with a larger field of view at a greater distance.

If not interested on the shapes of the structure while it is been inflated and only interested on certain straps then you would have to give up the large field of view of $8 \mathrm{ft}$ to something closer to $2 \mathrm{ft}$, change the dot pattern to a speckle pattern in order to create dots much smaller and have better lighting. Doing the test indoors will also provide more controls for better data as you are controlling the lighting and temperature extremes.

\section{B. Strain Gage Conclusions}

Measuring load in inflatable structures through utilization of calibrated strain gaged clevises is a difficult task due to a number of variables involved. Foremost, clevis strain can be effected by many factors including clevis bolt preload, bending loads, off-axis strap loading, and wide variability in the lower strain (and thus load) regions. Results are expected to improve when measuring higher strains in the higher load regions. Despite testing in the lower load regions, results from this test were promising and an improvement over prior testing of woven inflatable structures where friction in the weave can produce greater variability and uncertainty in loading. ${ }^{2}$ Six of the seven strain gaged calibrated clevises tracked fairly well with analytical predictions. In order to obtain better results the following suggestions are recommended:

1. Test in the higher strain and higher load regions.

2. Design a high stress/strain region in the clevis. This can prove to be difficult if also trying to test in the higher pressure regions or design in multiple clevises in a limited space.

3. Place the strain gage in a region on the clevis that only sees tension from the strap and no bending.

\section{General Conclusions and Forward Plan}

Photogrammetry has proven to be an effective method for measuring strain and load in the belly of fabric structures. Although results show variability, improvements are expected when testing in the higher strain regions (above 2,000 pounds for this test article). Improvements are also expected when moving toward utilizing a smaller speckle pattern for greater photogrammetry sampling.

Future testing on the Phase II article includes a Damage Tolerance Test to 9 psig. During the test, the structural restraint layer will be severed at pressure and load redistribution will be measured through photogrammetry and strain gaged clevises. To improve strain gage results, adding additional calibrated strain gages is desirable but currently beyond the resource scope. For photogrammetry improvement, a smaller photogrammetry speckle dot pattern will be utilized and the cameras will be moved closer to the test article. Additionally, testing indoors is preferred, but due to safety concerns of a large, highly loaded inflatable structure, it is not permitted. 


\section{References}

${ }^{1}$ D.M. Revilock, J.C. Thesken, T.E. Schmidt, B.S. Forsythe, “3D Digital Image Correlation of a Composite Overwrapped Pressure vessel During hydrostatic Pressure Tests”, 2007 SEM Annual Conference and Exposition on Experimental and Applied Mechanics.

${ }^{2}$ J.E. Edgecombe, H. M. de la Fuente, and G.D. Valle, "Damage Tolerance Testing of a NASA TransHab Derivative Woven Inflatable Module”, 2009 AIAA/ASME/ASCE/AHS/ASC Structures, Structural Dynamics, and Materials Conference, AIAA-2009-2167.

${ }^{3}$ J. Hinkle, A. Dixit, J.K. Lin, K. Whitley, J. Watson, G. Valle, "Design Development and Testing for an Expandable Lunar Habitat”, Space 2008 Conference and Exposition. 